\title{
Soil-Structure Interaction of Steel Pipe Culverts
}

\author{
Hany El Naggar \\ Associate Professor, Department of Civil and Resource Engineering, \\ Dalhousie University, Canada, \\ hany.elnaggar@dal.ca
}

Design of steel pipe culverts has evolved from the simplified ring compression method and the semiempirical Marston-Spangler method to the more sophisticated current design procedure specified in Section 12 of the AASHTO LRFD Bridge Design Specifications and Section 7 of the Canadian Highway Bridge Design Code (CHBDC), which considers the potential of compressive failure by either crushing or buckling. While the current design procedure appear to lead to reasonable results, a review of the factors affecting the magnitude of the pressure applied to the structure reveals that several factors known to affect the soil-structure interaction appear to have been neglected. These factors include the trench geometry and the relative stiffness of the existing and backfill soil and its accompanying anticipated soil nonlinearity. This paper presents a detailed finite-element analysis parametric study that investigates the accuracy and applicability of the current design procedures for culverts in partial trench installations when the aforementioned factors are considered.

Keywords: Steel culverts; Soil-structure interaction; 2D finite-element modeling, Partial trench installations. 